\section{Comparação Entre Diferentes Métodos Para Avaliar a Presença de Auto-Anticorpos Dirigidos ao Receptor de TSH em Pacientes Com Moléstia de Graves-Basedow}

\section{RESUMO}

Auto-anticorpos anti-receptores de TSH (TSHRAbs) foram avaliados por dois diferentes métodos [TRAb, como \% de inibição de ligação do TSH por anticorpos séricos e produção de AMP cíclico em cultura de células $\mathrm{CHO}$ expressando o receptor de TSH humano recombinante (CHO-rhTSHR)] em 52 pacientes (36F/16M) com moléstia de Graves-Basedow (DGB), tanto antes do tratamento como aos 6 e 12 meses de terapia contínua com metimazol (40$60 \mathrm{mg} /$ dia) e L-tiroxina ( $100 \mu \mathrm{g} / \mathrm{dia})$; outros 20 pacientes tireotóxicos $(12 \mathrm{~F} / 8 \mathrm{M})$ foram tratados com doses individualizadas de radioiodo. Os TSHRAbs determinados pelo radioreceptorensaio foram positivos em 47/52 pacientes $(90,4 \%)$ com valor médio \pm EPM de $56,7 \pm 3,9 \%$, diminuindo significantemente aos $6(40,5 \pm 3,2 \%)$ e 12 meses $(43,5 \pm 4,7 \%)$ de terapêutica, bem como após radioiodo $(30,7 \pm 4,5 \%)$. Os TSHRAbs foram discriminados pelo bioensaio em todos os 52 pacientes com DGB ativa (1122+409\%). Após 6 e 12 meses de terapêutica houve decréscimo (não significante) dos valores iniciais. Nenhum indivíduo do grupo controle normal $(n=80)$ apresentou TSHRAbs detectado por qualquer dos métodos. Portanto, a sensibilidade da pesquisa dos anticorpos pelo bioensaio, nos 52 pacientes com DGB ativa, foi maior que nos mesmos indivíduos avaliados pelo radioreceptorensaio. Houve correlação positiva $(r=0,59 ; p<0,001)$ entre TRAb e CHO-rhTSHR. Concluímos que a pesquisa dos TSHRAbs, realizada quer pelo radioreceptorensaio como pelo bioensaio, constitui recurso útil para se avaliar a atividade autoimune na DGB. (Arq Bras Endocrinol Metab 2001;45/6:563-569)

Unitermos: Moléstia de Graves-Basedow; TRAb; Anti-TPO; Células CHO; AMP cíclico; Receptor de TSH.

\begin{abstract}
Antibodies directed to the TSH receptor (TSHRAbs), detected by TRAb as TSHbinding inhibitory immunoglobulin, and cyclic AMP production by $\mathrm{CHO}$ cells expressing human TSH recombinant receptor (CHO-rhTSHR) were determined in 52 patients (36F/16M) with Graves' disease (DGB), both before and at 6 and 12 months of continuous treatment with metimazol ( $40-60 \mathrm{mg} / \mathrm{day})$ associated with L-thyroxine ( $100 \mu \mathrm{g} / \mathrm{day})$. Another group of 20 patients $(12 \mathrm{~F} / 8 \mathrm{M})$ was referred for radioiodine (RAI) treatment. The TSHRAbs were detected by radioreceptor assay in none of the 80 normal control individuals and in $47 / 52$ patients $(90.4 \%)$ with a mean \pm SEM value of $56.7 \pm 3.9 \%$. There was a significant decrease of mean TRAb values at 6 and 12 months of MMl + LT4 therapy. Six months after RAI, TRAb decreased significantly to $30.7 \pm 4.5 \%$. In contrast, TSHRAbs were determined by bioassay in none of the 80 normal control subjects but in all 52 patients with a mean \pm SEM of $1122 \pm 409 \%$. Similarly to TRAb there was a non-significant decrease at 6 and 12 months of MMI + LT4 therapy. Thus, the sensitivity of TSHRAbs detected by bioassay in 52 patients with active DGB seems to be greater than that detected by radioreceptor. In conclusion, the radioreceptor assay values as well as the bioassay for TSHRAbs may be useful for the diagnosis of active DGB. (Arq Bras Endocrinol Metab 2001;45/6:563-569)
\end{abstract}

Keywords: Graves-Basedow disease; TRAb; AntiTPO; CHO cells; Cyclic AMP; TSH receptor.

\section{artigo original}

\author{
Maria Silvia Cardia \\ Meyer Knobel \\ Nicolau Lima \\ Maria Lucia C.C. \\ Gianella-Netto \\ Humberto Cavalieve \\ Geraldo Medeiros-Neto
}

Unidade de Tireóide e Laboratório de Biologia Celular e Molecular de Tireóide (LIM-25), Disciplina de Endocrinologia, Departamento de Clínica Médica, Faculdade de Medicina da Universidade de São Paulo, SP. 
$\mathrm{O}$ HIPERTIREOIDISMO PRESENTE em pacientes com moléstia de Graves-Basedow (DGB) é causado por anticorpos estimuladores dirigidos ao receptor membranoso de TSH (TSHR) localizado entre outros elementos celulares, principalmente na célula folicular tireóidea. $\mathrm{Na}$ avaliação clínica do paciente tireotóxico, além de exames que definem a gravidade da hiperfunção tireóidea, a detecção de tais anticorpos estimuladores do receptor de TSH é particularmente relevante para $(1,2)$ : diagnóstico diferencial ocasional do hipertireoidismo; avaliação prognóstica da moléstia após tratamento clínico, cirúrgico ou actínico; predição da disfunção tireóidea fetal ou neonatal; predição da evolução da doença autoimune.

$\mathrm{Na}$ maioria dos laboratórios, quer de pesquisa quer de análises clínicas (1), os auto-anticorpos estimuladores do TSHR são mensurados pela sua capacidade de inibir a fixação de TSH marcado isotopicamente a membranas solúveis de células tireóideas purificadas de glândulas de suínos. O princípio deste método é simples, ou seja, os auto-anticorpos presentes no soro de pacientes com DGB competem com o TSH marcado com 125I para um número limitado de vagas trazidas pelo TSHR presente nas membranas porcinas. Todavia esta metodologia não distingue auto-anticorpos estimuladores daqueles que são apenas bloqueadores do TSHR, uma vez que ambos autoanticorpos se fixam a ele.

Para tentar distinguir os estimuladores dos bloqueadores, utilizou-se, inicialmente, células tireóideas em cultura permanente (FRTL-5). Mas a possibilidade de transfecção do gene do TSHR em células obtidas de ovário de hamster chinês $(\mathrm{CHO})$, tornou a metodologia mais exequível. As células CHO-rhTSHR são capazes de responder in vitro à ação estimulatória de TSH ou de soros contendo auto-anticorpos estimuladores, pela liberação de AMP cíclico $(\mathrm{AMPc})$ no meio de cultura, o qual pode ser mensurado por radioimunoensaio específico.

Neste trabalho avaliamos a presença de autoanticorpos dirigidos ao TSHR pelos dois métodos referidos, isto é, TRAb e CHO-rhTSHR, em pacientes com DGB.

\section{PACIENTES}

\section{Controles normais}

Para fins comparativos, utilizamos amostras de soro obtidas de 80 indivíduos hígidos, procedentes da zona urbana de São Paulo, sem doença tireóidea detectável por meios clínicos e laboratoriais e selecionados nos ambulatórios do Hospital das Clínicas, FMUSP.
Foram incluídos 39 indivíduos do sexo masculino e 41 do sexo feminino, com idade variável entre 17 e 53 anos (mediana: 26 anos).

\section{Portadores de Moléstia de Graves-Basedow}

Incluímos neste trabalho pacientes portadores de DGB, com ou sem exoftalmo, sem medicação antitireóidea atual, e não submetidos a terapêutica cirúrgica ou actínica. Alguns critérios de exclusão foram estabelecidos: glândulas tireóide com volume (avaliado por ultra-sonografia) maior que $80 \mathrm{~g}$, exoftalmo severo, idade acima de 60 anos, problemas cardiológicos com arritmia, insuficiência cardíaca, presença de diabetes ou outras moléstias graves necessitando intervenção médica. Procurou-se, igualmente, selecionar pacientes que pudessem vir ao Hospital das Clínicas da FMUSP com certa regularidade e assiduidade, e mantivessem adesão ao tratamento clínico, exceto aqueles com múltiplos tratamentos anteriores e aqueles provenientes de outros estados brasileiros.

O diagnóstico da DGB foi feito segundo a presença de bócio, sintomas e sinais de hipertireoidismo, níveis elevados de hormônios tireóideos e auto-anticorpos detectáveis no sangue.

Após confirmação laboratorial do quadro clínico de hipertireoidismo autoimune por testes apropriados de função tireóidea, avaliação volumétrica das glândulas por ultra-sonografia e mensuração de autoanticorpos (antiTPO, antiTg e TRAb), os pacientes selecionados $(\mathrm{n}=52,36$ do sexo feminino e 16 do sexo masculino, com idades entre 17 e 57 anos; mediana: 26 anos), foram instruídos a usar dieta com baixo conteúdo de iodo, por pelo menos um mês. A seguir foram prescritos 40-60mg de metimazol (MMI), diariamente, por 6 semanas, com a adição de L-tiroxina (L-T4) na dose de $100 \mu \mathrm{g} /$ dia a partir da sétima semana.

Os indivíduos foram, periodicamente, avaliados clínica e laboratorialmente, em ambulatório, quanto à função tireóidea e morfologia glandular por ultrasonografia.

Para a finalidade deste trabalho utilizamos os dados laboratoriais da fase basal (sem tratamento), e aos 6 e 12 meses após instituição da terapêutica combinada de MMI e L-T4.

Outro grupo de pacientes com DGB, recebeu tratamento actínico $(n=20,12$ do sexo feminino e 8 do sexo masculino, com idades entre 17 e 52 anos; mediana: 30 anos). Este era composto por pacientes que não responderam satisfatoriamente ao tratamento 
medicamentoso ou que não foram submetidos a esta modalidade terapêutica por apresentar bócios volumosos ou complicações (exoftalmo, alterações cardíacas, diabetes). Nestes pacientes igualmente avaliamos os títulos de TRAb, antiTPO e antiTg, precedendo e 60 dias após a dose de radioiodo (RAI).

\section{MÉTODOS}

\section{Reagentes químicos}

Quando não alternativamente especificado, os reagentes foram adquiridos da Sigma Chemical Co., St. Louis, MO, EUA e Life Technologies, Gaithersburg, MD, EUA.

\section{Cultura de células}

As células $\mathrm{CHO}$ expressando receptores humanos de TSH (CHO-rhTSHR) foram gentilmente cedidas pela Profa. Carine Maenhaut, Universidade Livre de Bruxelas, Bélgica. Desenvolvidas rotineiramente em meio RPMI suplementado com tripsina a $2,5 \%$, penicilina e estreptomicina, soro fetal bovino a $10 \%$, foram mantidas $\mathrm{em}$ incubador a $37^{\circ} \mathrm{C} \mathrm{em}$ atmosfera contendo $\mathrm{CO} 2$ a $5 \%$.

\section{Bioensaio com células CHO-rhTSHR}

Utilizamos duas linhagens de células transfectadas com o gene recombinante do hTSHR (JP-26) e não transfectadas (JP-02).

As duas linhagens foram semeadas em placas contendo 96 poços aglomerados (densidade final aproximada de $15 \times 10^{3}$ células/poço) contendo meio HBSS [meio de Hank com NaCl, HEPES ( $\mathrm{pH} 7,5$ ) $10 \mathrm{mM} / \mathrm{L}, 95,8$ gramas/L de sacarose e isobutilmetilxantina (IBMX) $0,5 \mathrm{mMol} / \mathrm{L}]$.

Após $24 \mathrm{~h}$ foram lavadas 2 vezes com tampão hipotônico (HBSS sem $\mathrm{NaCl}$ ) e após 48 h, alíquotas de soros (10mL), HBSS (controle negativo) e TSH recombinante humano ( $\mathrm{lmU} / \mathrm{L}$; Thyrogen, Genzyme Co., Cambridge, MA, EUA) foram adicionadas ao meio de cultura. Os ensaios foram feitos em pelo menos três replicatas e o procedimento seguiu a técnica de Vitti e cols. (3), com pequenas modificações. Após $2 \mathrm{~h}$ de incubação a $37^{\circ} \mathrm{C}$, o meio de cultura foi removido e congelado a $-20^{\circ} \mathrm{C}$ até a medida do AMP cíclico (AMPc).

O conteúdo de AMPc no meio extracelular foi determinado por RIE [Biotrack cAMP (125I) assay system, Amersham International, Little Chalfont, UK]. Os coeficientes de variação intra-ensaio e interensaio, foram, respectivamente, $11 \%$ e $13 \%$. Os resultados foram expressos como índice, calculado como: AMPc pmol (na presença do soro teste/AMPc pmol (na presença do soro normal) x 100. Foi con- siderado positivo um valor índice $>120 \%$ (superior à média obtida com soros normais $+2 \mathrm{DP}$ ). O coeficiente médio de variação interensaio, para 4 amostras com respostas positivas, foi de $12,3 \%$ (variação de $4,2 \%$ a $18,7 \%)$.

Com o intuito de investigar a influência de fatores estimuladores da tireóide, particularmente do IGF-1 naquelas amostras, realizamos experimentos utilizando soro de pacientes portadoras de acromegalia com níveis elevados do fator, a saber: $1.597 \mathrm{ng} / \mathrm{mL}$ (valores de referência normais para mulheres $>40$ anos $=141-389 \mathrm{ng} / \mathrm{mL}$; IRMA com extração, Diagnostic Systems Laboratories, Inc., Webster, TX, EUA) e $595 \mathrm{ng} / \mathrm{mL}$. Em ambos os casos a resposta do AMPc foi inferior a $120 \%$. Além disso, utilizamos preparações de IGF-1 (Growth-Prep, Australia) em concentrações de $50 \mathrm{ng} / \mathrm{mL}$ e $100 \mathrm{ng} / \mathrm{mL}$, respectivamente, que adicionadas ao meio de cultura em alíquotas adequadas por poço, igualmente provocaram respostas de AMPc menores que 120\%.

\section{Determinação do anticorpo anti-receptor de TSH (TRAb)}

Utilizamos radiobioensaio competitivo comercial (TSH receptor antibody assay, KRONUS, Dana Point, CA, EUA). Os resultados foram expressos em $\%$ de inibição da ligação do TSH-125I aos seus receptores (TBII) solubilizados pelos anticorpos presentes no soro analisado. Foram considerados positivos quando se encontravam acima de $15 \%$ (acima da média dos resultados obtidos com soros normais + 3DP). Para uma amostra com valor médio de $35 \%$, o coeficiente de variação interensaio foi de $12,2 \%$.

\section{Pesquisa de anticorpos antitireoglobulina (antiTg) e antiperoxidase (antiTPO)}

Estes auto-anticorpos foram determinados por RIE, mediante uso de estojos comerciais (DYNOtest antiTg, DYNOtest antiTPO, Brahms Diagnostica $\mathrm{GmbH}$, Berlin, Alemanha). Os coeficientes de variação intra e interensaio foram $8 \%$ e $9 \%$ e $7,2 \%$ e 12,2\%; os limites de sensibilidade de $30 \mathrm{U} / \mathrm{mL}$ e $15 \mathrm{U} / \mathrm{mL}$, respectivamente. São considerados positivos para antiTg valores maiores que $200 \mathrm{U} / \mathrm{mL}$ e antiTPO valores acima de $60 \mathrm{U} / \mathrm{mL}$ (níveis superiores à média $+3 \mathrm{DP}$ dos resultados obtidos com soros normais).

\section{Medida da Tireoglobulina}

A tireoglobulina sérica foi determinada por técnica imunoradiométrica, mediante uso de estojos comerciais (DYNOtest $\mathrm{Tg}$, Brahms Diagnostica $\mathrm{GmbH}$, 
Berlin, Alemanha). Os coeficientes de variação intra e interensaio, são, respectivamente, $9 \%$ e 10\%; sensibilidade mínima: $0,4 \mathrm{ng} / \mathrm{mL}$. Os valores de referência em 24 indivíduos normais variaram de 1,0 a $15,5 \mathrm{ng} / \mathrm{mL}$.

\section{Determinação do TSH, T3, T4 e T4 livre}

As concentrações séricas de T3, T4, T4 livre e TSH foram determinadas por técnica imunoenzimática, utilizando-se estojos comerciais da Baxter Diagnostics Inc., Deerfield, IL, EUA - STRATUS Automated System. Exibem, respectivamente, coeficientes de variação intra e interensaio de: TSH: 5,3\% e 6\%; T4: 7\% e 9\%; T3: 8\% e 9\%; T4L: 6\% e 7\%. As sensibilidades mínimas são: TSH: $0,05 \mu \mathrm{U} / \mathrm{mL}$; T4L: $0,4 \mathrm{ng} / \mathrm{dL}$. Os valores de referência são: TSH: 0,5$3,5 \mu \mathrm{U} / \mathrm{mL} ; \mathrm{T} 4: 4,5-12 \mu \mathrm{g} / \mathrm{dL} ; \mathrm{T} 3: \quad 80-210 \mathrm{ng} / \mathrm{dL}$; T4L: $0,6-2,0 \mathrm{ng} / \mathrm{dL}$.

\section{Análise estatística}

Empregamos o teste $t$ de Student para análise de diferenças entre valores médios e respectivos desvios da média. Os valores não transformados em log de TRAb e CHO-rhTSHR/AMPc foram submetidos à análise de correlação usando-se o coeficiente de Spearman. Como a distribuição destas variáveis não é normal, optou-se pela transformação logarítmica e obteve-se a correlação pelo coeficiente de Pearson.

\section{RESULTADOS}

\section{TRAb}

Em indivíduos normais, a atividade TBII foi sempre inferior a $10 \%$, com valor médio de $3,74 \pm 0,37(\mathrm{EPM}) \%$. Em pacientes com DGB não tratada, o valor médio foi de $56,7 \pm 3,9 \%$ (oscilando entre 10 e $84 \%$ ). Apenas 5 pacientes em 52 examinados apresentaram valores nor- mais de TRAb $(9,6 \%$ dos pacientes com quadro clínico e ativo de DGB). Na tabela 1 estão expostos os resultados da avaliação da função tireóidea, anteriores e posteriores ao tratamento medicamentoso e actínico.

Analisamos os valores de TRAb decorridos 6 e 12 meses de terapêutica contínua associando-se MMI (40-60mg/dia) e L-T4 (100 $\mu \mathrm{g} / \mathrm{dia})$. Constatou-se que durante a terapêutica, os valores diminuíram significantemente em relação aos valores basais (tabela 2). A análise de variância, igualmente foi significativa com $\mathrm{p}=0,0495$.

O grupo de pacientes com DGB submetido ao RAI apresentou, também, declínio significativo do TRAb, com valor médio de $30,7 \pm 4,5 \%(\mathrm{p}<0,05 \mathrm{em}$ relação à média basal). Neste grupo, 3 de 17 pacientes

\begin{tabular}{|c|c|c|c|}
\hline FASE & $\begin{array}{l}\text { ANTI-TPO } \\
(\mathrm{U} / \mathrm{mL})\end{array}$ & $\begin{array}{c}\text { TRAb } \\
\text { (\% inibição) }\end{array}$ & $\begin{array}{l}\text { CHO-rhTSHR/AMPc } \\
\text { (\% incremental) }\end{array}$ \\
\hline Basal $(n=52)$ & $3514 \pm 520$ & $56,7 \pm 3,9$ & $1122 \pm 409$ \\
\hline 6 meses & $3929 \pm 551$ & $40,5 \pm 3,2^{*}$ & $516 \pm 93$ \\
\hline 12 meses & $2134 \pm 435^{\star}$ & $43,5 \pm 4,7^{\star}$ & $984 \pm 426$ \\
\hline $\begin{array}{l}\text { Pré-radioiodo } \\
(n=20)\end{array}$ & $3788 \pm 662$ & $53,5 \pm 6,4$ & nd \\
\hline Pós radioiodo & $2252 \pm 435^{\star}$ & $30,7 \pm 4,5^{\star}$ & nd \\
\hline Valores normais & $\leq 60$ & $\leq 15$ & $\leq 120$ \\
\hline
\end{tabular}

* Significantemente diferente $(p<0,05)$ comparando-se com 0 basal; nd: não disponível

Tabela 1. Testes de função tireóidea dos pacientes portadores de moléstia de Graves-Basedow antes e após o tratamento medicamentoso e antes e após o tratamento actínico (média \pm epm).

\begin{tabular}{|c|c|c|c|c|c|}
\hline TRATAMENTO & $\begin{array}{c}\mathrm{T3} \\
\text { (ng/dL) }\end{array}$ & $\begin{array}{c}\mathrm{T} 4 \\
(\mu \mathrm{g} / \mathrm{dL})\end{array}$ & $\begin{array}{l}\text { T4 livre } \\
\text { (ng/dL) }\end{array}$ & $\begin{array}{c}\text { TSH } \\
(\mu \mathrm{U} / \mathrm{mL})\end{array}$ & $\begin{array}{l}\text { Tireoglobulina } \\
\text { (ng/mL) }\end{array}$ \\
\hline \multicolumn{6}{|l|}{ MEDICAMENTOSO } \\
\hline Basal $(n=52)$ & $364,8 \pm 22,9$ & $17,6 \pm 0,6$ & $3,8 \pm 0,2$ & $<0,05$ & $91,0 \pm 28,3$ \\
\hline 6 meses & $167,3 \pm 8,3$ & $9,5 \pm 0,5$ & $1,7 \pm 0,2$ & $3,7 \pm 1,8$ & $76,0 \pm 18,3$ \\
\hline 12 meses & $161,0 \pm 6,3$ & $8,9 \pm 0,4$ & $1,3 \pm 0,1$ & $3,3 \pm 1,1$ & $74,0 \pm 16,5$ \\
\hline \multicolumn{6}{|l|}{ ACTíNICO } \\
\hline Basal $(n=20)$ & $397,1 \pm 37,6$ & $19,8 \pm 1,3$ & $4,7 \pm 0,5$ & $<0,05$ & $139,0 \pm 43,4$ \\
\hline 2 meses pós-RAl & $242,2 \pm 22,1$ & $11,6 \pm 0,9$ & $1,9 \pm 0,2$ & $<0,05$ & $72,0 \pm 22,6$ \\
\hline \multicolumn{6}{|l|}{ Valores normais } \\
\hline (faixa de variação) & $80-210$ & $4,5-12,0$ & $0,6-2,0$ & $0,5-3,5$ & $1,0-15,5$ \\
\hline
\end{tabular}


(17,6\%) exibiram resultados negativos de TRAb. Quando todos os pacientes com DGB tratados clinicamente e submetidos ao RAI $(n=69)$ foram considerados, $61(88,4 \%)$ apresentaram resultados positivos. Os valores positivos foram concordantes com níveis positivos de resposta do AMPc em células CHO-rhTSHR em todos os pacientes.

\section{CHO-rhTSHR/AMPc}

A liberação de AMPc após estímulo pelos soros dos pacientes com DGB mostrou-se elevada em todos os pacientes não tratados $(\mathrm{n}=52)$ com valor médio de $1122,4 \pm 39,4 \%$. Decorridos 6 e 12 meses de tratamento observou-se queda dos valores incrementais de $\mathrm{AMPc}$, mas não houve significância estatística pela dispersão dos valores individuais (tabela 2). Infelizmente, por indisponibilidade dos soros dos portadores de DGB submetidos ao RAI em quantidades suficientes para realizar a pesquisa de TSHRAbs por esta técnica,
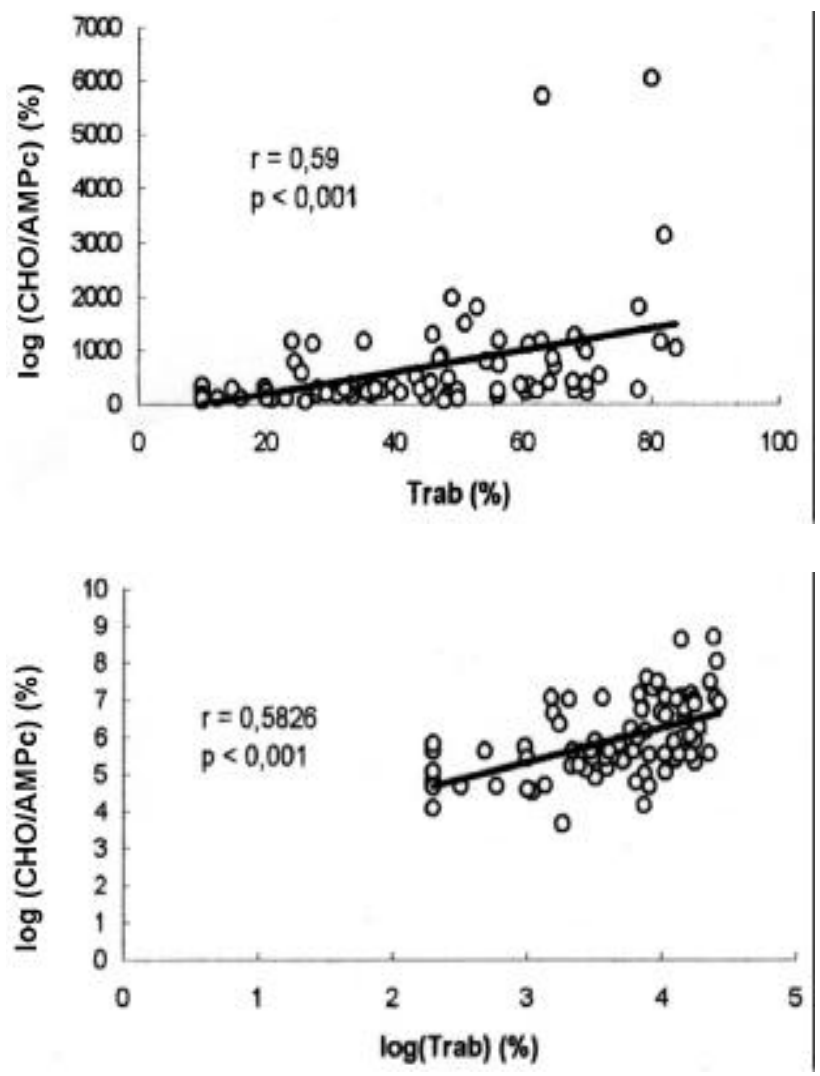

Figura 1. Correlação entre TRAb e AMP cíclico de células $\mathrm{CHO}-$ rhTSHR: valores expressos em \% (quadro superior) e transformação logarítmica (quadro inferior), de resultados de TRAb e CHO-rhTSHR/AMPc em pacientes não submetidos à terapêutica. Em ambas situações a correlação foi positiva e significativa. não podemos apresentar os resultados.

A correlação entre valores obtidos de TRAb e CHO-rhTSHR/AMPc foi positiva e significativa tanto em valores expressos em \% de inibição ou liberação de cAMP, respectivamente, como em transformação logarítmica (figura 1) na fase precedendo a terapêutica. Após o tratamento, combinando-se os dados obtidos aos 6 e 12 meses, esta correlação manteve-se igualmente positiva e significativa $(\mathrm{r}=0,82$; $\mathrm{p}<0,001)$.

\section{AntiTPO}

Os valores de antiTPO mostraram-se elevados em $93,3 \%$ dos pacientes examinados, com valor basal médio de $3.514 \pm 520 \mathrm{U} / \mathrm{mL}$. Não houve correlação significativa entre os valores de antiTPO e os demais auto-anticorpos, tanto na fase basal como após tratamento clínico (MMI e L-T4) ou actínico.

Decorridos 6 meses de terapêutica, não houve

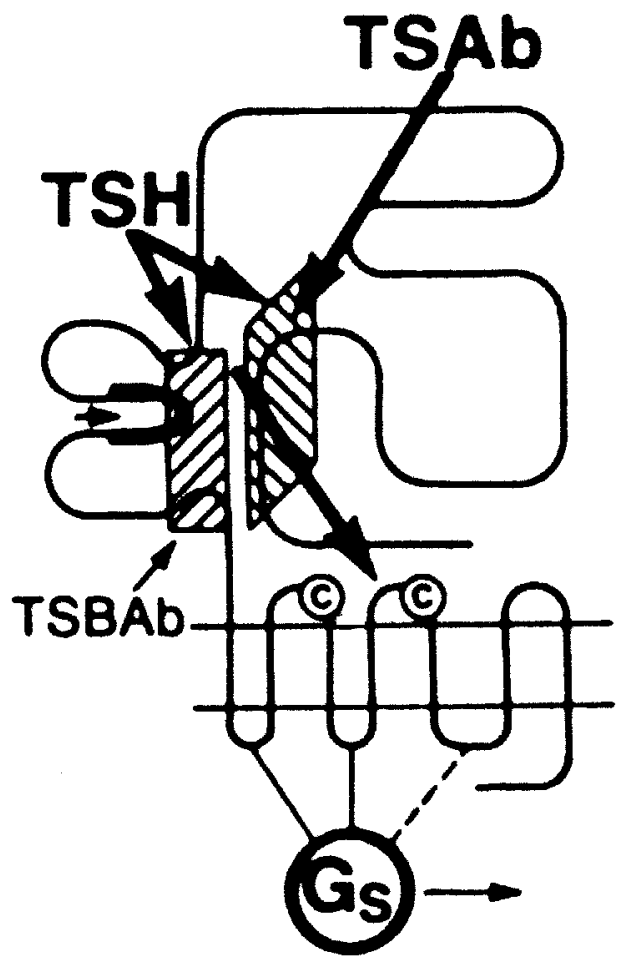

Figura 2. Modelo concebido do receptor de TSH humano. Na região extracelular do receptor, o ligante específico (TSH) age tanto na região aminoterminal como na carboxiterminal. Por outro lado, os anticorpos estimuladores (TSAb) mensurados pelo teste CHO-rhTSHR/AMPc exercem função de maior geração de AMP cíclico na área demarcada na porção aminoterminal. Anticorpos bloqueadores (TSBAb) mensurados pelo TRAb teriam sua ação na área indicada, na porção carboxiterminal [adaptado de Akamizu e cols. (6)]. 
queda significativa de auto-anticorpos antiTPO $(3.929 \pm 551 \mathrm{U} / \mathrm{mL})$, que somente ocorreu decorridos 12 meses de tratamento $(2.134 \pm 425 \mathrm{U} / \mathrm{mL})$.

Em 52 pacientes examinados, apenas $3(5,7 \%)$ apresentaram resultado discordante em relação ao teste por CHO-rhTSHR/AMPc. Após tratamento com RAI, o valor médio de antiTPO caiu para $2252 \pm 359 \mathrm{U} / \mathrm{mL}$, porém a diferença não foi estatisticamente significante.

\section{DISCUSSÃO}

Os anticorpos que agem estimulando o TSHR são os causadores do hipertireoidismo da DGB, possivelmente envolvidos na etiopatogenia do exoftalmo e do mixedema pretibial $(1,2,4,5)$. Anticorpos bloqueadores do receptor de TSH foram encontrados em alguns pacientes com tireoidite crônica de Hashimoto ou hipotireoidismo idiopático $(4,6)$. Para melhor entender o mecanismo pelo qual os diferentes tipos de anticorpos anti-TSHR promovem diferentes efeitos biológicos (estimulador/bloqueador) é necessário conhecer os respectivos epitopos presentes no TSHR. Entre as tentativas de determiná-los, alguns autores (4-6) usaram técnicas de mutagênese dirigida a sítios específicos, bem como criaram moléculas quiméricas do TSHR. Sabe-se que os anticorpos estimuladores deste receptor são parte de uma população de IgG altamente heterogênea e podem ser dirigidos a diferentes epitopos do TSHR, conforme o tipo de população de pacientes estudada, cada qual com uma constituição genética diferente (5). Por exemplo, em número relativamente grande de pacientes japoneses com moléstias tireóideas autoimunes causadas por auto-anticorpos $\operatorname{TRAb}(4,6)$, o epítopo funcional mais importante para o estímulo está na porção N-terminal do domínio extracelular, enquanto o auto-anticorpo bloqueador atua na porção carboxi-terminal da mesma porção extracelular (figura 2). Diante desta natureza diversa de açôes e possíveis locais diferentes de atuação, admite-se que o método comumente utilizado na prática médica, ou seja, o TRAb seja mensurado pela sua capacidade de bloquear o locus ou epítopo de ligação do TSH ao seu receptor, mantendo quantidades variáveis de TSH marcado sob forma livre, não ligado ao seu epítopo específico. Por outro lado, mesmo que o paciente com DGB tenha anticorpos estimuladores, agindo em outros epitopos, o teste TRAb não os identifica e muito menos os quantifica. Diante deste quadro surgiram, em passado recente, testes biológicos que exploram a capacidade de células tireóideas em cultura ou células tireóideas FRTL5 de produzirem AMP cíclico quando estimuladas por TSH (o ligante fisiológico e específico) ou por IgGs agindo em epitopos apropriados do receptor de TSH. No entanto, o uso de células tireóideas em cultura, quer provenientes de glândulas obtidas em cirurgia, quer em sistema celular permanente (FRTL-5), é trabalhoso e sujeito a contaminação, com resultados discordantes e contraditórios. Recentemente passou-se a usar células CHO que expressam o TSHR clonado (3,7-10). Muito recentemente outro sistema celular foi introduzido por Costagliola e cols. (11) usando linha de células leucêmicas K562 igualmente expressando aquele receptor. Em ambos, todavia, a quantificação do processo de estímulo por IgG ou soro de paciente com DGB é realizada pela liberação de AMPc emergente no meio. Nestas circunstâncias, quanto maior a produção deste mensageiro maior a atividade estimulatória do anticorpo anti-receptor de TSH.

Em revisão recente, Morris (2) resume a utilidade clínica dos ensaios empregados na determinação dos TSHRAbs em 3 situações principais: 1) ocasionalmente, no diagnóstico diferencial do hipertireoidismo; 2) na avaliação prognóstica da DGB após tratamento com drogas antitireóideas, e 3) na predição de disfunção tireóidea fetal ou neonatal. Segundo Davies (12), esta última indicação constitui ainda a única situação onde a bioatividade do TSHRAbs deveria ser conhecida. O objetivo seria a predição do hipertireoidismo (anticorpos estimuladores) ou hipotireoidismo (anticorpos bloqueadores) neonatal.

Segundo a literatura, os ensaios radioreceptores exibem elevada sensibilidade (entre $70 \%$ a $90 \%$ em portadores de $\mathrm{DGB}$ ) e especificidade, enquanto nos bioensaios a sensibilidade varia de $80 \%$ a $90 \%$ (13). As maiores vantagens dos radiorreceptorensaios sobre os bioensaios estão na sua disponibilidade comercial, na relativa facilidade de execução e custo operacional. Podem ser realizados sem a necessidade de cultura de células e recursos complementares associados. Como aqueles primeiros medem apenas a ligação ao receptor, não diferenciam o TRAb com efeito estimulador do TRAb com efeito inibidor. Contudo, parece que são mais sensíveis na detecção do estimulador (2). Apesar disso, cabe assinalar que, na literatura, existe certo consenso de que os bioensaios, mais dispendiosos e engenhosos não seriam necessários na prática clínica atual (14). Isto porque, na maioria das situações de suspeita de disfunção tireóidea, o diagnóstico pode ser feito pela história clínica, exame físico, medida dos hormônios tireóideos, concentração de TSH e captação de radioiodo. Em cenários clínicos pouco usuais, estes bioensaios poderiam melhorar a abordagem diagnóstica em doenças tireóideas autoimunes suspeitas.

De forma genérica o teste de $\mathrm{CHO}$ - 
rhTSHR/AMPc é mais sensível e específico do que o TRAb $(7,8,10)$ atingindo cerca de $94 \%$ de positividade em pacientes com DGB não tratada. Por outro lado, o teste de CHO-rhTSH/AMPc declina, temporalmente, com o progredir da terapêutica clínica, atingindo positividade em apenas $36 \%$ dos pacientes eutireóideos após 12 meses de droga antitireóidea (7).

Em nossos pacientes o teste de TRAb considerado positivo foi encontrado em $90,4 \%$ dos não tratados, declinando, após 6 e 12 meses de terapêutica clínica ou após radioiodo terapêutico (tabela 2). Ao contrário do observado na literatura, não apresentaram queda do AMPc no bioensaio com CHO-rhTSHR, embora fosse observada diminuição do valor médio inicial de $1122 \%$ para 516\% aos 6 meses de tratamento. Paradoxalmente, o nível de resposta do AMPc das células CHO-rhTSHR ao estímulo por auto-anticorpos anti-TSHR elevou-se aos 12 meses de tratamento clínico. Uma possível influência no resultado seria a menor adesão ao tratamento clínico entre 6 e 12 meses. Outra possibilidade seria que o ensaio radiorreceptor convencional tenha sido superior ao bioensaio, no que diz respeito à evolução da doença. No entanto, tanto na fase basal como no período pós-tratamento, houve consonância de positividade do teste de TRAb com os valores de $\mathrm{CHO}-$ rhTSH/AMPc. A falta de significância para valores médios de CHO-rhTSHR/AMPc se deve à grande dispersão dos dados individuais. Igualmente os valores de antiTPO foram consonantes, tanto com os de TRAb como com os de CHO-rhTSHR/AMPc, seja na fase basal como durante a terapêutica clínica.

Estes aspectos apontam para a hipótese de que os clones de células imunocompetentes produtoras de IgGs, estimuladores ou bloqueadores, anti-receptor de TSH, ou dirigidos contra a peroxidase tireóidea, teriam o mesmo comportamento em relação ao tratamento clínico, com declínio progressivo segundo o tempo da terapêutica.

O tratamento com RAI conduziu a valor médio significantemente mais baixo tanto de TRAb como de antiTPO.

Em conclusão, os resultados sugerem que o bioensaio para detectar TSHRAbs parece ser mais sensível e pode ser útil para diagnóstico da DGB e mostram que apresenta elevada concordância com o teste de TRAb e o nível de anticorpos antiTPO. Entretanto, se considerarmos custo e simplicidade, aquela técnica apresenta desvantagem sobre o ensaio radioreceptor.

\section{REFERÊNCIAS}

1. Orgiazzi J. Anti-TSH receptor antibodies in clinical practice. Endocrinol Metab Clin N Am 2000;29:339-53.
2. Morris JC Jr. Clinical use of immunological assays of TSH receptor autoantibodies. Thyroid Today 1998;21:1-7.

3. Vitti $P$, Elisei R, Tonacchera M, Chiovato L, Mancusi F, Rajo $\mathrm{T}$, et al. Detection of thyroid-stimulating antibody using Chinese hamster ovary cells transfected with cloned human thyrotropin receptor. J Clin Endocrinol Metab 1993;76:499503.

4. Tahara K, Ishikawa N, Yamamoto K, Hirai A, Ito K, Tamura Y, et al. Epitopes for thyroid-stimulating and blocking autoantibodies on the extracellular domain of the human TSH receptor. Thyroid 1997;7:867-77.

5. Rapoport B, Chazenbalk, GD, Jaume JC, McLachlan SM. The thyrotropin (TSH) receptor: interaction with TSH and autoantibodies. Endocr Rev 1998;19:673-716.

6. Akamizu T, Kohn LD, Huratani H, Sayo M, Tahara K, Nakao K. Hashimoto thyroiditis with heterogeneous antithyrotropin receptor antibodies: unique epitopes may contribute to the regulation of thyroid function by the antibodies. J Clin Endocrinol Metab 2000;85:2116-21.

7. Persani L, Tonacchera M, Beck-Peccoz P, Vitti $P$, Mammoli $C$, Chiovato $L$, et al. Measurement of CAMP accumulation in Chinese hamster ovary cells transfected with the recombinant TSH receptor: a new bioassay for human thyrotropin. J Endocrinol Invest 1993;16:1 1-9.

8. Murakami M, Miyashita K, Kalazaki S, Saito S, Yamada M, Iruchizima $\mathrm{T}$, et al. Clinical usefulness of thyroid-stimulating antibody measurement using Chinese Hamster Ovary cels expressing human TSH receptor. Eur J Endocrinol $1995 ; 133: 80-6$.

9. Morgenthaler NG, Pampel I, Aust G, Saissler J, Scherbaun WA. Application of a bioassay with $\mathrm{CHO}$ cells for the routine detection of stimulating and blocking autoantibodies to the TSH receptor. Horm Met Res 1998;30:162-8.

10. Wallaschofski M, Paschke R. Detection of thyroid stimulating (TSAb) and thyrotropin stimulation blocking (TSBAb) antibodies with $\mathrm{CHO}$ cell lines expressing different TSH-receptor numbers. Clin Endocrinol 1999;50:365-72.

11. Costagliola S, Morgenthaler NG, Hoermann R, Badenhoop $\mathrm{K}$, Struck J, Freitag $\mathrm{D}$, et al. Second generation assay for thyrotropin receptor antibodies has superior diagnostic sensitivity for Graves' disease. J Clin Endocrinol Metab 1999;84:90-7.

12. Davies TF. Thyroid-stimulating hormone receptor antibodies: the calm after the storm after the calm? Mayo Clin Proc 1988;63:736-9.

13. Morris JC, Hay ID, Nelson RE, Jiang N-S. Clinical utility of thyrotropin-receptor antibody assays: comparison of radioreceptor and bioassay methods. Mayo Clin Proc 1988;81:3257-60.

14. Davies TF. Thyroid controversy: stimulating antibodies. J Clin Endocrinol Metab 1998;83:3777-85.

\section{Endereço para correspondência:}

Geraldo Medeiros-Neto

Hospital das Clínicas

Av. Dr. Enéas C. Aguiar 255, $8^{\circ}$ bl. 3

05403-900 São Paulo, SP

Fax: (011) 211-5194

e.mail: medneto@uol.com.br 